\title{
Impact of obesity on the thyroid profile, long-term experience at the General Hospital of Mexico, "Dr. Eduardo Liceaga"
}

\author{
Jessica G. Sosa-López ${ }^{1}$, Pedro Alarcón-González¹, Virginia H. Sánchez-Hernández ${ }^{1 *}$, \\ Antonio Cruz-Estrada ${ }^{1}$, Claudia A. Aguilar-Serralde², and Adolfo A. Velasco-Medina ${ }^{2}$ \\ ${ }^{1}$ Department of Internal Medicine; ${ }^{2}$ Clínica de Atención Integral al Paciente con Diabetes y Obesidad (CAIDO). Hospital General de México \\ "Dr. Eduardo Liceaga", Mexico City, Mexico
}

\begin{abstract}
Introduction: The main alterations reported in the thyroid profile of patients with obesity show an increase in TSH and T3 levels and a decrease in T4 levels. These alterations have been reported in $25 \%$ of obese patients and are considered more as a consequence rather than stemming from obesity itself. However, these alterations have not been evidenced in the Mexican population. Objective: The objective of the study was to determine the association between TSH, T3, T4 levels, and obesity grade. Material and methods: This is a retrospective analytical cross-sectional study conducted between the years 2015 and 2019. Obese patients who had altered TSH, free T4 and total T3, and free T3 levels were included in the study. Patients diagnosed with diabetes, thyroid diseases, undergoing treatment with levothyroxine, or taking drugs that alter thyroid function tests were excluded. Spearman's rank correlation coefficient was used to establish a correlation between obesity grade and thyroid hormones levels. Results: $A$ positive correlation was found between TSH levels and obesity grade ( $r=0.13$; $p=0.049)$. A negative correlation was found between obesity grade and free $T 4(r=-0.26 ; p=0.000275)$ and total T4 levels $(r=-0.18 ; p=0.029)$. While analyzing free T3 and total T3 levels and T4/T3 ratio, the descriptive analysis showed an increase in $T 3$ values as the obesity grade increased, with no correlation found. Conclusions: Obesity grade is associated with alterations in thyroid function that can affect the normal range of thyroid hormones levels.
\end{abstract}

Key words: Obesity. Thyroid profile. Thyroid hormones.

\section{Introduction}

Slightly or moderately elevated thyroid stimulating hormone $(\mathrm{TSH})$ and triiodothyronine $\left(\mathrm{T}_{3}\right)$ values, that is, above the normal range, have been described in patients with obesity. This elevation is currently considered more as a consequence rather than stemming from obesity itself ${ }^{1}$. In general, it is suggested that the increase in TSH is an adaptive mechanism in obese patients, a response of the hypothalamus-pituitary-thyroid axis to weight gain. Because, if increased TSH levels were the primary event, an increase in serum thyroid hormones would also be expected ${ }^{2}$.

Various studies have shown that TSH levels are slightly higher in the obese population than in the non-obese population and that weight reduction in this population causes normalization of thyroid hormone levels ${ }^{3,4}$; in other words, some studies show an effect on thyroid function conditioned by weight loss in obese patients ${ }^{5,6}$.

Internationally, high concentrations of TSH have been reported in $25 \%$ of obese subjects ${ }^{1}$. The main reported

\section{Correspondence:}

*Virginia H. Sánchez-Hernández E-mail: vickysanmd@yahoo.com 0185-1063/@ 2020 Sociedad Médica del Hospital General de Mexico. Published by Permanyer. This is an open access article under the CC BYNC-ND license (http://creativecommons.org/licenses/by-nc-nd/4.0/).
Available online: 22-01-2021 Rev Med Hosp Gen Mex. 2021;84(1):4-10 www.hospitalgeneral.mx
article under the $\mathrm{CC} B Y-$ 
alterations in the thyroid profile of obese patients are increased TSH and T3, with a positive association between TSH levels and body mass index (BMI ${ }^{7-9}$, and a negative association between $\mathrm{BMI}$ and serum tetraiodothyronine $\left(\mathrm{T}_{4}\right)^{10}$.

In Mexico, a prevalence of primary hypothyroidism stands at $8 \%$, subclinical hypothyroidism at $6 \%$, and alterations in the thyroid profile secondary to obesity are estimated to occur in $23 \%$ of obese patients ${ }^{11}$.

TSH elevation in obese patients is mainly assigned to leptin, the adipose-derived hormone. A correlation between TSH and leptin levels has been demonstrated in obese subjects ${ }^{12}$, and leptin concentrations are higher in obese patients. A slow signaling pathway mediated by the JAK/STAT pathway is known to generate the expression of the thyrotropin-releasing hormone (TRH) gene in the hypothalamic paraventricular nucleus and thus the increased synthesis and secretion of TSH and thyroid hormones ${ }^{13}$. Circulating leptin levels are correlated with the degree of total adiposity ${ }^{14}$. In the case of obesity, increased leptin is considered evidence of "leptin resistance." This increase in TSH, and therefore in T3, could be interpreted as a defense mechanism of the body against weight gain. The high conversion rate reported from T4 to T3 in obese patients has also been interpreted as a defense mechanism, capable of counteracting the accumulation of fat due to increased energy expenditure ${ }^{15}$.

Some other neurotransmitters and hormones that influence weight, such as the Y-neuropeptide and the alpha-melanocyte-stimulating hormone, which are influenced by leptin, also regulate TSH production ${ }^{16}$. Leptin also affects thyroid deiodinase activity with activation of T4-to-T3 conversion, thus supporting the concept of an inverse relationship between T4 and leptin. An increase in total T3 or free T3 levels in obese patients has been reported as well as an association between progressive fat accumulation with increasing TSH and T3 levels. This finding suggests a high T4 to T3 conversion in patients with central obesity, due to increased deiodinase activity as a compensatory mechanism. Reverse T3 or 3.3',5'-triiodothyronine (T3r) is mainly a product of $\mathrm{T} 4$ degradation in peripheral tissues: Liver, kidney, and muscle T3r levels; it is a biologically inactive product of T4 degradation. It is also secreted by the thyroid gland, but under normal physiological conditions, the amounts are practically insignificant. The measurement of T3r concentration in serum reflects both tissue supply and T4 metabolism and identifies conditions that favor this particular T4 degradation pathway ${ }^{17}$.
Despite high plasma TSH levels, TSH receptors are expressed less in the adipocytes of obese individuals. This reduced expression of the TSH receptor may induce decreased action of thyroid hormone, further increasing plasma concentrations of TSH and T3, which are a condition of peripheral thyroid hormone resistance ${ }^{18}$.

Despite what has been reported in international literature, the behavior of thyroid hormone levels in obese patients in Mexico is unknown. There was a study carried out at the Mexican Institute of Social Security which comprised 52 morbidly obese patients, conducted at the Obesity Clinic, Department of Endocrinology, by Montoya-Morales et al.; however, no correlation was found between BMI and TSH levels in that study ${ }^{11}$.

The aim of this study is to determine whether there is an association between thyroid hormone levels and obesity grade, documenting the long-term experience of the Comprehensive Care Clinic for patients with diabetes and obesity.

\section{Material and methods}

A retrospective, analytical cross-sectional study was conducted. Medical records of patients referred to the Comprehensive Care Clinic for patients with Diabetes and Obesity at the General Hospital of Mexico "Dr. Eduardo Liceaga" were analyzed between February 2015 and February 2019. The inclusion criteria were patients with any obesity grade classified according to the WHO (Grade 1 being considered those patients with BMI of $30-34.9 \mathrm{~kg} / \mathrm{m}^{2}$, Grade 2 with BMI of $35-39.9 \mathrm{~kg} / \mathrm{m}^{2}$, and Grade 3 with BMl of $\geq 40 \mathrm{~kg} / \mathrm{m}^{2}$ ). Patients between 18 and 65 years old were included, who initially had their serum thyroid hormone values measured on admission.

Patients diagnosed with type 2 diabetes mellitus, hypothyroidism, or any other thyroid disease and patients that had been prescribed any drug for altered thyroid function (lithium, amiodarone, iodide, carbamazepine, rifampicin, phenobarbital, and glucocorticoids) were excluded from the study.

Measurements of height, weight, BMI, TSH, free T3, total T3, free $\mathrm{T} 4$ and total $\mathrm{T} 4$, and $\mathrm{T} 3 / \mathrm{T} 4$ ratio were obtained. The normal range of TSH was $0.38-4.0 \mathrm{mU} / \mathrm{l}$, free T3 2.39-6.79 mU/l, total T3 0.87-1.78 mU/l, free T4 0.58-1.64 mU/l, and total T4 6.09-12.23 mU/l, taking TPO antibodies greater than $5 \mathrm{IU} / \mathrm{ml}$ as a positive cutoff value.

SPSS software version 22 for Windows was used for statistical analysis. Descriptive statistics (proportions, mean, and standard deviation) were used for the 
Table 1. Population characteristics and serum thyroid hormone levels (mean and standard deviation) according to patient's gender

\begin{tabular}{|l|c|c|c|c|}
\hline Characteristics & Males $(\mathbf{n}=\mathbf{4 1}) \mathbf{2 2} \%$ & Females $(\mathbf{n}=\mathbf{1 4 5}) \mathbf{7 8 \%}$ & Total (186) & $\mathbf{p}$ value \\
\hline Patient age (years) & $41.65 \pm 10.13$ & $44.60 \pm 13.28$ & $43.95 \pm 12.69$ & 0.19 \\
\hline Weight on admission to the clinic (kg) & $124.18 \pm 30.39$ & $105.20 \pm 23.96$ & $109.38 \pm 26.62$ & 0.000040 \\
\hline Weight at 1 year's follow-up (kg) & $109.24 \pm 29.03$ & $96.25 \pm 22.31$ & $99.12 \pm 24.47$ & 0.002 \\
\hline Height (m) & $1.66 \pm 0.75$ & $1.56 \pm 0.76$ & $1.58 \pm 0.08$ & $<0.0001$ \\
\hline Body mass index on admission to the clinic (BMI) & $44.42 \pm 8.68$ & $42.94 \pm 8.61$ & $43.27 \pm 8.62$ & 0.336 \\
\hline Body mass index (BMI) at 1 year's follow-up & $39.30 \pm 9.61$ & $39.41 \pm 8.68$ & $39.38 \pm 8.86$ & 0.945 \\
\hline TSH levels (mU/L) & $4.17 \pm 2.70$ & $4.69 \pm 4.77$ & $4.57 \pm 4.36$ & 0.511 \\
\hline Free T3 levels (mU/L) & $3.18 \pm 0.63$ & $3.13 \pm 0.50$ & $3.14 \pm 0.53$ & 0.638 \\
\hline Total T3 levels (mU/L) & $1.28 \pm 0.88$ & $1.21 \pm 0.64$ & $1.22 \pm 0.69$ & 0.608 \\
\hline Free T4 levels (mU/L) & $0.88 \pm 0.16$ & $0.87 \pm 0.16$ & $0.87 \pm 0.16$ & 0.899 \\
\hline Total T4 levels (mU/L) & $8.78 \pm 2.03$ & $8.55 \pm 1.57$ & $8.59 \pm 1.68$ & 0.506 \\
\hline T4/T3 ratio (mU/L) & $8.34 \pm 4.42$ & $7.62 \pm 2.26$ & $7.77 \pm 2.82$ & 0.229 \\
\hline
\end{tabular}

analysis of quantitative dependent variables, in this case: Age, weight, height, BMl, and thyroid hormone levels.

Inferential statistics (Spearman's rank correlation coefficient) were performed to establish if there was a correlation between obesity grade and serum TSH, free T3, total T3, free T4, and total T4 levels. Pearson's Chisquared test was applied to analyze if there was a difference in the prevalence of alterations in the thyroid profile according to the obesity grade. All the hypothesis contrast tests with $p<0.05$ were deemed statistically significant.

\section{Results}

In total, 186 records were analyzed of patients with a complete thyroid profile at the time of admission to the comprehensive care clinic for patients with diabetes and obesity.

Comparisons of population characteristics show that there is no difference by sex in terms of age, BMI, and thyroid hormone levels. Statistically significant differences in weight and height were found, with these values being higher in men than in women (Table 1). According to the WHO obesity grading, 28 patients (15.1\%) were classified as obesity Grade 1 (BMI 30$\left.34.9 \mathrm{~kg} / \mathrm{m}^{2}\right) ; 45$ patients $(24.2 \%)$ as obesity Grade 2 (BMI $35-39.9 \mathrm{~kg} / \mathrm{m}^{2}$ ), and 113 patients $(60.7 \%$ ) as obesity Grade $3\left(\mathrm{BMI} \geq 40 \mathrm{~kg} / \mathrm{m}^{2}\right)$.
The diagnosis of primary hypothyroidism was shown in 20 patients (10.75\%); 64 patients (34.41\%) presented alterations in the thyroid profile secondary to obesity: Eight patients $(4.30 \%)$ presented with subclinical hypothyroidism and 94 patients (50.54\%) were reported as euthyroid (Fig. 1).

With regard to patients diagnosed with subclinical hypothyroidism, primary hypothyroidism, and alterations in the thyroid profile secondary to obesity, $80.4 \%$ were women and $19.6 \%$ were men, while the percentage of women in whom any of these diagnoses were made was $51 \%$ and in men $43.9 \%$ (Fig. 2).

When the levels of thyroid hormones were compared in the three groups of subjects categorized according to BMI, only a statistically significant difference was found in free T4 levels. These values were higher in patients with obesity Grade 3 (Table 2).

When doing the correlation analysis, a positive correlation was found between TSH levels and weight $(r=0.19 ; p=0.007)$; as well as a correlation between TSH levels and obesity grade $(r=0.13 ; p=0.049)$. As for free T4 and total T4 levels, a negative correlation was found with the obesity grade, at $(r=-0.26$; $p=0.000275)$ and $(r=0.18 ; p=0.029)$, respectively. Although an increase in the mean values of free T3, total T3, and $\mathrm{T} 4 / \mathrm{T} 3$ ratio was observed in the analysis of the descriptive variables, as the obesity grade increased, no correlation with the obesity grade was found while doing the statistical analysis. 


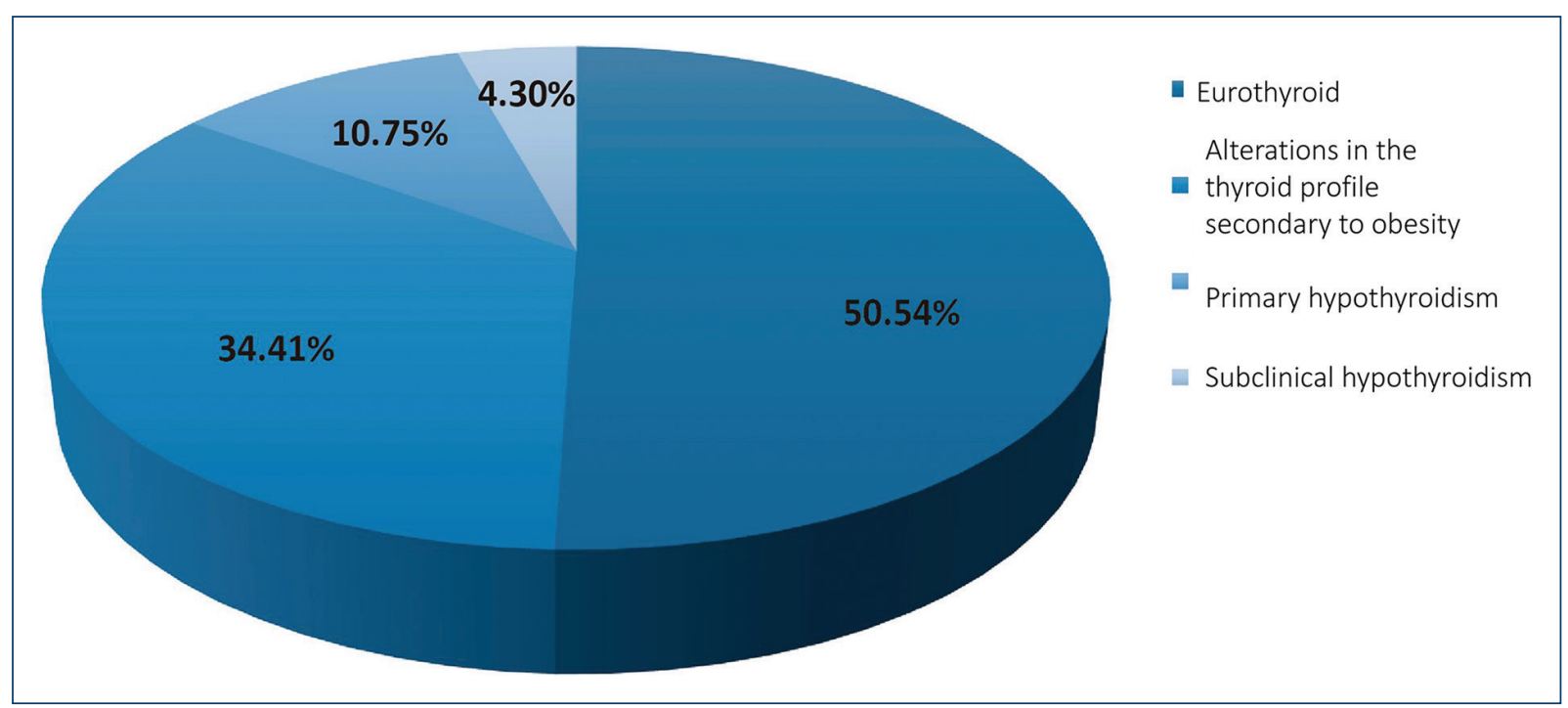

Figure 1. Thyroid function in patients with obesity represented in percentages.

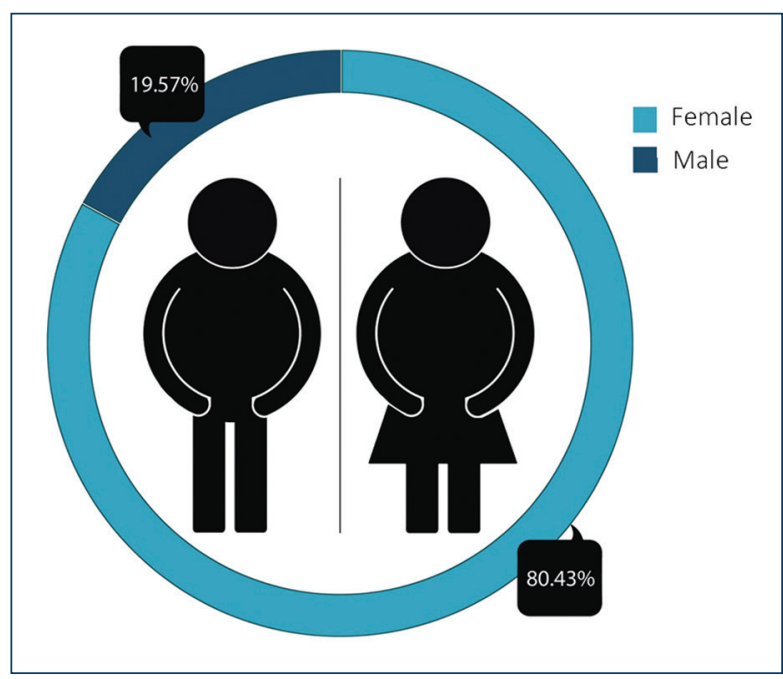

Figure 2. Percentage of patients diagnosed with subclinical hypothyroidism, primary hypothyroidism, and alterations in the thyroid profile secondary to obesity, grouped according to gender.

The percentage of patients diagnosed with alterations in the thyroid profile secondary to obesity, subclinical hypothyroidism, and primary hypothyroidism according to the obesity grade was $18.5 \%$ for patients with Grade 1 obesity, $25 \%$ for patients with Grade 2 obesity, and $56.5 \%$ for patients with Grade 3 obesity. However, when Pearson's Chi-squared test was applied, no significant difference was found between the three groups $(p=0.367)$ (Fig. 3).

\section{Discussion}

In this study, $50.55 \%$ of patients reported euthyroidism; a prevalence of primary hypothyroidism was estimated at $10.75 \%$ and $4.30 \%$ for subclinical hypothyroidism. About $34.40 \%$ of patients presented alterations in the thyroid profile secondary to obesity, which is similar to a study carried out in Mexico at the Mexican Institute of Social Security in 52 patients with morbid obesity. The study was conducted at the obesity clinic of the Endocrinology Department by Montoya-Morales et al. ${ }^{11}$ estimating a prevalence of primary hypothyroidism at $8 \%$, subclinical hypothyroidism at $6 \%$, and $23 \%$ of patients presented thyroid function alterations secondary to obesity (characterized by elevated TSH and/or elevated total or free T3 and free T4 with normal antithyroid antibodies). These data are very similar to those reported in the international literature where elevated TSH concentrations have been reported in 25\% of obese patients ${ }^{1}$. This increase in prevalence is probably related to some other factors involved in TSH elevation. These include circadian rhythm, age, and some markers of insulin resistance ${ }^{19,20}$.

Regarding the prevalence of subclinical hypothyroidism in our study, a prevalence of $4.3 \%$ was estimated, which is similar to what is reported in the international literature, which ranges between 4 and 10\% depending on the gender, age, and population studied ${ }^{21,22}$. This ranges between $10.5 \%$ and $25 \%$ in patients with obesity, while Kitahara et al. reported a prevalence of $10.5 \%$ for patients with BMI between 30 and $67 \mathrm{~kg} / \mathrm{m}^{223}$. 
Table 2. Serum thyroid hormone levels (mean and standard deviation) according to patients' body mass index

\begin{tabular}{|l|c|c|c|c|}
\hline Thyroid hormones & Obesity Grade $\mathbf{1}(\mathbf{n}=\mathbf{2 8})$ & Obesity Grade $\mathbf{2}(\mathbf{n}=\mathbf{4 5})$ & Obesity Grade $\mathbf{3}(\mathbf{n}=\mathbf{1 1 3})$ & $\mathbf{p}$ value \\
\hline TSH (mU/L) & $5.64 \pm 5.25$ & $5.14 \pm 6.93$ & $4.08 \pm 2.41$ & 0.15 \\
\hline Free T3 (mU/L) & $3.16 \pm 0.48$ & $3.11 \pm 0.63$ & $3.15 \pm 0.50$ & 0.93 \\
\hline Total T3 (mU/L) & $1.13 \pm 0.17$ & $1.15 \pm 0.24$ & $1.26 \pm 0.84$ & 0.62 \\
\hline Free T4 (mU/L) & $0.90 \pm 0.16$ & $0.85 \pm 0.16$ & $0.80 \pm 0.13$ & 0.003 \\
\hline Total T4 (mU/L)I & $8.76 \pm 1.83$ & $8.35 \pm 1.25$ & $8.27 \pm 1.32$ & 0.28 \\
\hline T4/T3 ratio (mU/L) & $7.46 \pm 1.47$ & $7.36 \pm 1.72$ & $7.97 \pm 3.29$ & 0.51 \\
\hline
\end{tabular}

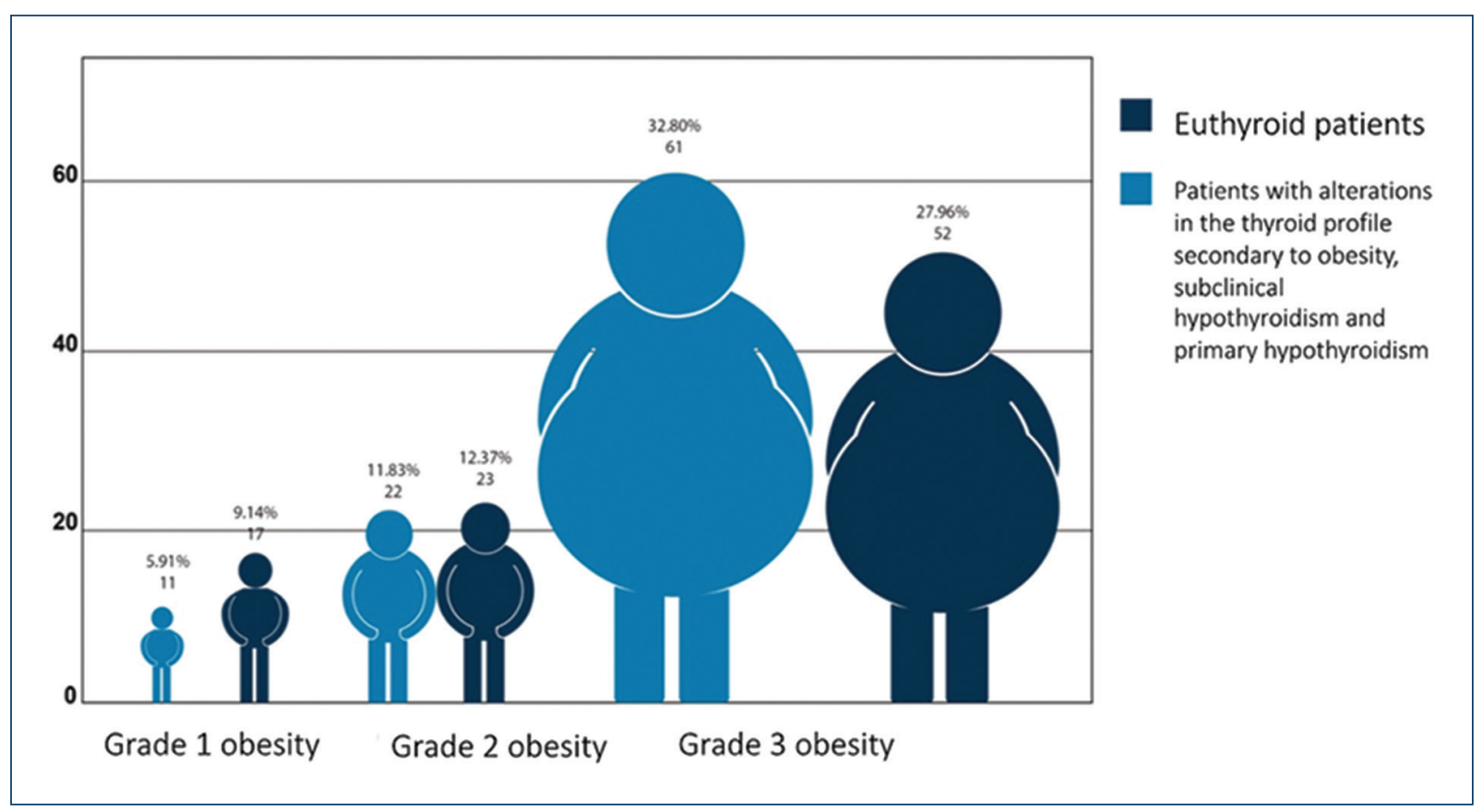

Figure 3. Percentage of patients diagnosed with subclinical hypothyroidism, primary hypothyroidism, and alterations in the thyroid profile secondary to obesity, grouped according to obesity grade.

As for the behavior of thyroid hormone levels, a positive correlation was found between TSH and weight levels $(r=0.19 ; p=0.007)$. Regarding obesity grade $(r=0.13 ; p=0.049)$, a negative correlation between obesity grade and free $\mathrm{T} 4(r=-0.26 ; p=0.000275)$ and total T4 levels $(r=-0.18 ; p=0$. 029), which resonates with other studies mentioned in the international literature. These studies report main alterations in patients with obesity such as an increase in TSH and T3, there being a positive association between TSH levels and body mass index $(\mathrm{BMI})^{7,8}$, as well as a negative association between body mass index and serum tetraiodothyronine $(\mathrm{T} 4)^{10}$.
These correlation ratios are very similar to those cited in a Nigerian study of 76 obese children and adolescents versus non-obese control patients, where serum TSH, T3, and T4 levels were measured. BMI $(p<0.001)$, T3 $(p<0.01)$, TSH $(p<0.001)$, and T3/T4 ratio $(p<0.001)$ were significantly higher in obese children and adolescents than non-obese children and adolescents. BMI was positively correlated with triiodothyronine levels $(r=0.230 ; p<0.05)$, TSH $(r=0.272$; $p<0.02)$, and T3/T4 ratio $(r=0.232 ; p<0.05)^{9}$.

In our study, while doing the analysis of free T3, total T3 levels, and T4/T3 ratio, although an increase in T3 values was observed in the analysis of the descriptive 
variables, as the obesity grade increased, no correlation was found $(r=0.04 ; p=0.616)$ in the statistical analysis. We consider that the lack of correspondence for the determination of the total concentration of thyroid hormones was a limitation of the study, as it was a retrospective study; and that the increase in T3 is dependent on $T 3 r$, being considered biologically inactive at a cellular level and without a mechanism of action in obese patients ${ }^{17}$.

In another study carried out in Caucasian women with obesity, thyroid function was assessed and its possible relationship with body mass index (BMI), leptin, adiponectin, and insulin sensitivity. Obese women with $\mathrm{BMl}>40 \mathrm{~kg} / \mathrm{m}^{2}$ were found to have higher serum TSH levels than those with a BMI $<40 \mathrm{~kg} / \mathrm{m}^{2}$ $(p<0.01)$. TSH was correlated with BMI $(r=0.44$, $p=0.01)$, leptin $(r=0.41, p=0.01)$, leptin/BMl ratio $(r=0.33, p=0.03)$, body surface area $(r=0.26, p=0.05)$, HOMA-IR $(r=0.245, p=0.05)$, and inversely with adiponectin $(r=-0.25, p=0.05)^{12}$.

Although correlation ratios were low in our study, it has been reported that morbid obesity $(\mathrm{BMI}>$ or $=40 \mathrm{~kg} / \mathrm{m}^{2}$ ) is associated with alterations in thyroid function, with subclinical hypothyroidism being the most reported alteration ${ }^{24}$. This resonates with what was observed in our study, since the percentage of patients with alterations in the thyroid profile secondary to obesity, subclinical hypothyroidism, and primary hypothyroidism was up to $56.5 \%$ for patients with obesity Grade $3\left(\mathrm{BMl}>\right.$ or $\left.=40 \mathrm{~kg} / \mathrm{m}^{2}\right)$.

Regarding the evidence of thyroid autoimmunity in obese patients, the Third National Health and Nutrition Examination Survey (NHANES III) showed that thyroid antibodies do not differ in morbidly obese patients and in the general population ${ }^{25}$, which is very similar to the findings in our study, where the evidence of antibodies in $4.3 \%$ of patients was corroborated. The lack of evidence of autoimmunity in this group of patients is in accordance with the explanation that the increase in TSH and T3 levels is a response mechanism against weight gain. This leads to counteracting the accumulation of fat by increasing energy expenditure ${ }^{15}$, coupled with a condition of peripheral thyroid hormone resistance, because TSH receptors are expressed less in the adipocytes of obese individuals ${ }^{18}$.

Some studies have already begun to analyze population-adjusted cutoff values specifically in patients with obesity. In a representative study of the adult population in Spain that included 3928 patients without thyroid disease, with negative or normal antithyroid antibodies, measurements of free TSH, T3, and T4 levels were made. The reference range for TSH was adjusted as follows: In the overweight category (BMI $25-29.9 \mathrm{~kg} / \mathrm{m}^{2}$ ); $0.5-5.9 \mathrm{mlU} / \mathrm{mL}$ in the obesity category (BMI $30-39.9 \mathrm{~kg} / \mathrm{m}^{2}$ ); and $0.7-7.5 \mathrm{mlU} / \mathrm{mL}$ in the morbid obesity category (BMl greater than $\left.40 \mathrm{~kg} / \mathrm{m}^{2}\right)^{26}$.

In our study, average TSH levels according to obesity grade were 1.28-5.64 $\pm 5.25 \mathrm{mU} / \mathrm{l}$ for Grade 1 obesity (BMI $\left.30-34.9 \mathrm{~kg} / \mathrm{m}^{2}\right) ; 0.29-5.14 \pm 6.93 \mathrm{mU} / \mathrm{l}$ for Grade 2 obesity (BMI $35-39.9 \mathrm{~kg} / \mathrm{m}^{2}$ ), and $0.68-4.08 \pm 2.41 \mathrm{mU} / \mathrm{l}$ for Grade 3 obesity (BMI of $\geq 40 \mathrm{~kg} / \mathrm{m}^{2}$ ).

\section{Conclusions}

Our conclusion, according to our findings, is that the grade of obesity is associated with alterations in thyroid function that can affect the normal range of thyroid hormone levels. Alterations present in thyroid hormone levels and the actual diagnosis of thyroid disease in obese patients can pose an actual challenge. The values taken as a reference in the non-obese population and applied to the obese population can probably lead to an inadequate diagnosis, especially in the diagnosis of subclinical hypothyroidism and primary hypothyroidism. Thus, TSH levels should probably not be the only parameter to be considered when diagnosing hypothyroidism in obese patients. The absence or evidence of autoimmunity, together with the measurement and analysis of the whole thyroid profile, is also parameters to consider.

\section{Conflicts of interest}

The authors declare that they have no conflicts of interest.

\section{Ethical disclosures}

Protection of human and animal subjects. The authors declare that no experiments were performed on humans or animals for this study.

Confidentiality of data. The authors declare that they have followed the protocols of their work center on the publication of patient data.

Right to privacy and informed consent. The authors declare that no patient data appear in this article.

\section{References}

1. Reinehr T. Obesity and thyroid function. Mol Cell Endocrinol. 2010;316:165-71.

2. Santini F, Marzullo P, Rotondi M, Ceccarini G, Pagano L, Ippolito S, et al. Mechanisms in endocrinology: the crosstalk between thyroid gland and adipose tissue: signal integration in health and disease. Eur J Endocrinol. 2014;171:R137-52. 
3. Reinehr T, Isa A, de Sousa G, Dieffenbach R, Andler W. Thyroid hormones and their relation to weight status. Horm Res. 2008;70:51-7.

4. Reinehr T, Andler W. Thyroid hormones before and after weight loss in obesity. Arch Dis Child. 2002;87:320-3.

5. Neves J, Oliveira SC, Souteiro P, Pedro J, Magalhães D, Guerreiro V, et al. Effect of weight loss after bariatric surgery on thyroid-stimulating hormone levels in patients with morbid obesity and normal thyroid function. Obes Surg. 2018;28:97-103.

6. Chikunguwo S, Brethauer S, Nirujogi V, Pitt T, Udomsawaengsup S Chand $B$, et al. Influence of obesity and surgical weight loss on thyroid hormone levels. Surg Obes Relat Dis. 2007;3:631-5; discussion 635-6.

7. Fox CS, Pencina MJ, D'Agostino RB, Murabito JM, Seely EW, Pearce EN et al. Relations of thyroid function to body weight: cross-sectional and Iongitudinal observations in a community-based sample. Arch Intern Med. 2008;168:587-92

8. Knudsen N, Laurberg P, Rasmussen LB, Bülow I, Perrild H, Ovesen L, et al. Small differences in thyroid function may be important for body mass index and the occurrence of obesity in the population. J Clin Endocrinol Metab. 2005;90:4019-24.

9. Emokpae MA, Obazelu PA. The association of triiodothyronine-to-thyroxine ratio with body mass index in obese Nigerian children and adolescents. Med Sci (Basel). 2017;5:36.

10. Al-Musa HM. Impact of obesity on serum levels of thyroid hormones among euthyroid Saudi adults. J Thyroid Res. 2017;2017:5739806.

11. Montoya-Morales DS, Tapia-González MA, Alamilla-Lugo L, Sosa-Caballero A, Muñoz-Solís A. Jiménez-Sánchez M. Alteraciones de la función tiroidea en pacientes con obesidad mórbida. Rev Med Inst Mex Seguro Soc. 2015;53 Suppl 1:S18-22.

12. Lacobellis G, Ribaudo MC, Zappaterreno A, Lannucci CV, Leonetti F. Relationship of thyroid function with body mass index, leptin, insulin sensitivity and adiponectin in euthyroid obese women. Clin Endocrinol (Oxf). 2005;62:487-91

13. Duntas LH, Biondi B. The interconnections between obesity, thyroid function, and autoimmunity: the multifold role of leptin. Thyroid. 2013:23:646-53.
14. Popovic V, Duntas L. Leptin TRH and ghrelin: influence on energy homeostasis at rest and during exercise. Horm Metab Res. 2005;37:533-7.

15. Longhi S, Radetti G. Thyroid function and obesity. J Clin Res Pediatr Endocrinol. 2013:5 Suppl 1:40-4

16. Bandurska-Stankiewicz E. Thyroid hormones-obesity and metabolic syndrome. Thyroid Res. 2013;6 Suppl 2:A5.

17. Jameson L, de Groot L, de Kretser D, Giudice, L, Grossman A, Potts T, et al. Endocrinology: Adult and Pediatric. Philadelphia, PA: Elsevier; 2016. p. $1350-98$

18. Biondi B. Thyroid and obesity: an intriguing relationship. J Clin Endocrinol Metab. 2010:95:3614-7.

19. Pearce SH, Brabant G, Duntas LH, Monzani F, Peeters RP, Razvi S, et al. 2013 ETA guideline: management of subclinical hypothyroidism. Eur Thyroid J. 2013; 2:215-28

20. Bremner AP, Feddema P, Leedman PJ, Brown SJ, Beilby JP, Lim EM, et al. Age-related changes in thyroid function: a longitudinal study of a community-based cohort. J Clin Endocrinol Metab. 2012;97:1554-62.

21. Canaris GJ, Manowitz NR, Mayor G, Ridgway EC. The Colorado thyroid disease prevalence study. Arch Intern Med. 2000;160:526-34.

22. Vanderpump MP, Tunbridge WM, French JM, Appleton D, Bates D, Clark F, et al. The incidence of thyroid disorders in the community: a twenty-year follow-up of the Whickham survey. Clin Endocrinol. 1995;43:55-68.

23. Kitahara CM, Platz EA, Ladenson PW, Mondul AM, Menke A, de González $\mathrm{AB}$. Body fatness and markers of thyroid function among U.S. men and women. PLoS One. 2012;7:e34979.

24. Rotondi M, Leporati P, La Manna A, Pirali B, Mondello T. Raised serum TSH levels in patients with morbid obesity: is it enough to diagnose subclinical hypothyroidism? Eur J Endocrinol. 2009;160:403-8.

25. Hollowell JG, Staehling NW, Flanders WD, Hannon WH, Gunter EW, Spencer CA, et al. Serum TSH, T(4), and thyroid antibodies in the United States population (1988 to 1994): National health and nutrition examination survey (NHANES III). J Clin Endocrinol Metab. 2002:87:489-99.

26. Valdés S, Maldonado-Araque C, Lago-Sampedro A, Lillo-Muñoz JA, Garcia-Fuentes E, Perez-Valero V, et al. Reference values for TSH may be inadequate to define hypothyroidism in persons with morbid obesity: Di@bet.es study. Obesity (Silver Spring). 2017;25:788-93. 